\title{
Contributions of visible and invisible pores to reactive transport in dolomite
}

\author{
B.M. Tutolo ${ }^{\text {* }}$, A.J. Luhmann², X.-Z. Kong ${ }^{3}$, B. Bagley4 , D. Alba-Venero5, \\ N. Mitchell ${ }^{1}$, M.O. Saar ${ }^{3,4}$, W.E. Seyfried Jr. ${ }^{4}$
}

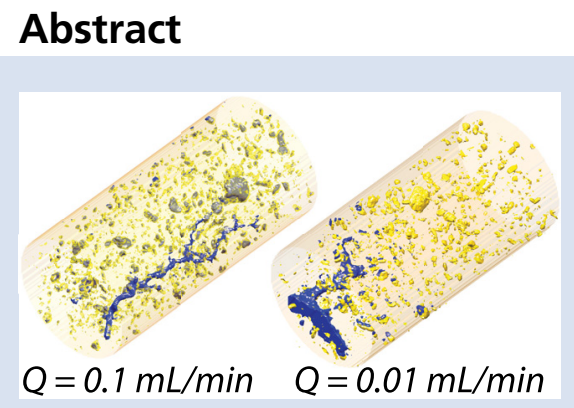

Recent technical advances have demonstrated the importance of pore-scale geochemical processes for governing Earth's evolution. However, the contribution of pores at different scales to overall geochemical reactions remains poorly understood. Here, we integrate multiscale characterisation and reactive transport modelling to study the contribution of pore-scale geochemical processes to the hydrogeochemical evolution of dolomite rock samples during $\mathrm{CO}_{2}$-driven dissolution experiments. Our results demonstrate that approximately half of the total pore volume is invisible at the scale of commonly used imaging techniques. Comparison of pre- and postexperimental analyses demonstrate that porosity-increasing, $\mathrm{CO}_{2}$-driven dissolution processes preferentially occur in pores $600 \mathrm{~nm}-5 \mu \mathrm{m}$ in size, but pores $<600 \mathrm{~nm}$ in size show no change during experimental alteration. This latter observation, combined with the anomalously high rates of trace element release during the experiments, suggests that nanoscale pores are accessible to through-flowing fluids. A three dimensional simulation performed directly on one of the samples shows that steady state pore-scale trace element reaction rates must be $\sim 10 \times$ faster than that of dolomite in order to match measured effluent concentrations, consistent with the large surface area-to-volume ratio and high reactivity of these pores. Together, these results yield a new conceptual model of pore-scale processes, and urge caution when interpreting the trace element concentrations of ancient carbonate rocks.

Received 20 December 2019 | Accepted 31 May 2020 | Published 8 July 2020

\section{Introduction}

Carbonate rocks, comprised of calcite, dolomite, and/or aragonite, have been abundant both spatially and temporally throughout Earth's history. Carbonate reservoirs hold more than $60 \%$ of the world's remaining oil and $40 \%$ of its natural gas, and have thus historically occupied a significant proportion of the global energy landscape (Tucker and Wright, 2009). Looking forward, these same hydrocarbon-trapping characteristics have also made them important targets for geologic carbon dioxide $\left(\mathrm{CO}_{2}\right)$ storage as the global energy economy transitions away from fossil fuels (Crawshaw and Boek, 2013).

Nonetheless, carbonate rocks are notorious for their often complex pore structures and lack of clear porosity-permeability relationships (Archie, 1952; Tucker and Wright, 2009). To this end, numerous recent studies have examined the hydrogeochemical evolution of carbonates using a combination of imaging and geochemical analyses, often with a specific focus on $\mathrm{CO}_{2}$ injection for geologic $\mathrm{CO}_{2}$ storage (GCS) or Enhanced Oil Recovery (EOR) (Luhmann et al., 2014; Luquot and Gouze, 2009; Smith et al., 2013; Wunsch et al., 2013). This work has generally concentrated on the dissolution of primary carbonate minerals, and coupled changes in porosity and permeability during reaction with dissolved $\mathrm{CO}_{2}$ (Smith et al., 2013; Tutolo et al., 2014), although a number of studies have examined the mobility of trace elements during $\mathrm{CO}_{2}$-driven dissolution of the primary carbonate minerals (Navarre-Sitchler et al., 2013; Wunsch et al., 2013; Luhmann et al., 2014). Many of these studies have observed non-stoichiometric mobilisation of trace elements during carbonate dissolution, where observed concentrations of trace elements are as much as an order of magnitude higher than would be expected from measured $\mathrm{Ca}$ or $\mathrm{Mg}$ concentrations. Some evidence demonstrating the exceptional mobility of such trace elements in pure calcite crystals is available in the literature (e.g., Stipp et al., 1992); nevertheless, the pore-scale mechanisms for trace element mobilisation remain poorly constrained.

With analytical revolutions over the past several decades, our ability to analyse geochemical processes at smaller and smaller scales has grown, such that processes which were largely theoretically inferred in the final decades of the $20^{\text {th }}$ century are now routinely observable in laboratories around the world. This analytical revolution has led to the understanding that

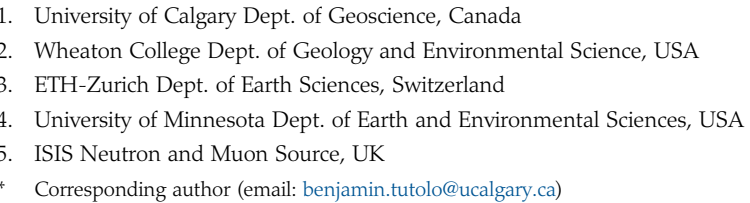


pore-scale processes, i.e. those occurring at the scale of individual pores in a rock, in fact govern the bulk (i.e. continuum-scale) geochemical interactions between rocks and fluids (e.g., Li et al., 2006; Molins et al., 2012; Plümper et al., 2017; Ma et al., 2019). Indeed, some have argued that the study of pore-scale geochemical processes should be considered a discipline in its own right (Steefel et al., 2015). This newfound recognition of the importance of pore-scale geochemical processes, combined with our growing knowledge of the size distribution of pores in geologic media (e.g., Anovitz and Cole, 2015), has led to the question: what is the relative reactivity of a rock's various pore sizes? In other words, although we now understand the importance of geochemical processes occurring at the scale of individual pores, we do not yet have a quantitative understanding of the relative role of different pore sizes in controlling bulk, continuumscale geochemical processes. Here, we present new multiscale neutron- and x-ray-based analyses of dolomite rock cores exposed to hydrothermal experiments to address the question of how the various pores sizes present in dolomite rocks impact their bulk hydrogeochemical evolution.

\section{Methods and Results}

Details of hydrothermal flow-through experiments were previously provided by Luhmann et al. (2014), but are summarised here to provide context for the presented, new results. Nine experiments were performed on $\sim 1.3 \mathrm{~cm}$ (diameter) $\times 2.6 \mathrm{~cm}$ (length) dolomite cores at $100^{\circ} \mathrm{C}$ and 150 bar pore fluid pressure and 200 bar confining pressure to simulate fluid-rock interaction in high $\mathrm{pCO}_{2}$ carbonate reservoirs. Injected solutions contained 1 molal $\mathrm{NaCl}$ and 0.65 molal $\mathrm{CO}_{2}$. Experiments lasted from 61 minutes to 9 days, with the duration being a function of the injection rate and the time which it took for permeability to begin to increase exponentially.

A wide variety of geochemical techniques suggest that the cores used in our experiments are almost entirely comprised of nearly stoichiometric dolomite, and electron microprobe (EMP) analyses confirm that the dolomite is geochemically homogeneous at the scale of interrogation, i.e. at mapping resolutions of $\sim 2 \mu \mathrm{m}$ with a beam diameter of $10 \mu \mathrm{m}$ (Luhmann et al., 2014). Spot analyses of $\mathrm{Sr}$ and $\mathrm{Mn}$ are in good agreement with the bulk geochemical analysis, again confirming that the measured trace elements are embedded within the dolomite structure rather than present as a discrete phase. Assuming that the measured cations are incorporated within the dolomite structure gives the formula:

$$
\mathrm{Ca}_{1.02} \mathrm{Mg}_{0.98} \mathrm{Ba}_{0.00003} \mathrm{Fe}_{0.0037} \mathrm{Mn}_{0.00076} \mathrm{Sr}_{0.00010}\left(\mathrm{CO}_{3}\right)_{2} \text {. }
$$

In spite of the homogeneous distribution of trace elements $\mathrm{Ba}$, $\mathrm{Mn}$, and Sr, their concentrations in effluent fluids far exceeded that expected from stochiometric dolomite dissolution in all samples. In the present study, we calculate the Ca normalised release ratio of trace element $i$ from the core according to:

$$
\text { Release Ratio }=\left(C_{i, f} / C_{C a, f}\right) /\left(C_{i, r} / C_{C a, r}\right),
$$

where $C$ indicates concentration, and the subscripts $f$ and $r$ indicate fluid and rock, respectively. Ca was used for these calculations, but virtually identical results would be achieved if $\mathrm{Mg}$ was used, since $\mathrm{Ca}$ and $\mathrm{Mg}$ concentrations were very similar in all samples. Plotting the release ratios against the cumulative water-to-rock ratio (calculated by normalising the cumulative mass of injected water by the mass of the core) demonstrates that $\sim 10 \times$ the amount of most trace cations in the cores, as compared to the major dolomite cations, was recovered during the dissolution experiments, with $\mathrm{Ba}$ and $\mathrm{Mn}$ being extracted at significantly faster rates than Sr (Fig. 1). The non-stoichiometric dissolution of trace elements suggests that the dissolution process continued even after the solution approached equilibrium with respect to dolomite. However, core-scale porosity changes, as measured by XRCT, agree well with the volumetric removal of dolomite calculated from effluent $\mathrm{Ca}$ and $\mathrm{Mg}$ concentrations (Luhmann et al., 2014). XRCT imagery also demonstrates that porosity changes during the experiments occurred largely in channels connecting large pores in the fluid flow path, and, to some degree, augmented pre-existing pores (see Graphical Abstract, caption in Supplementary Information).

The present study was initiated to provide insight into the roles of specific pore sizes in increasing sample porosity/ permeability and facilitating trace element recovery. We hypothesised that pores at scales invisible in the XRCT imagery allowed the reactant brines to penetrate into the dolomite and selectively remove the minor, less compatible elements without dissolving significant amounts of the dolomite itself. To test this hypothesis, we performed a series of Small and Ultra-Small Angle Neutron Scattering ((U)SANS) measurements to complement the previously published XRCT imagery. More information about these analyses is given in the Supplementary Information, however, briefly, (U)SANS measurements permit quantitative

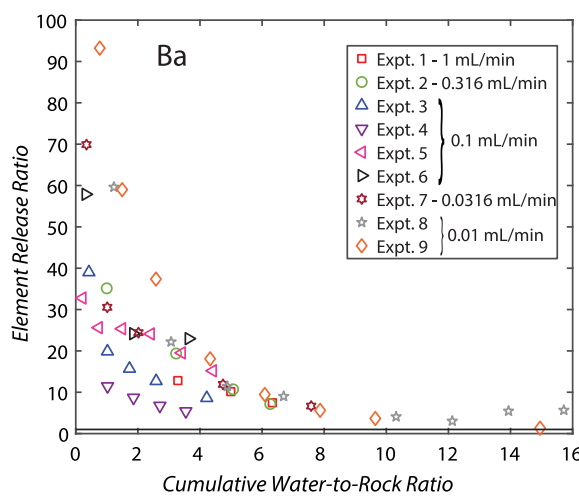

(a)

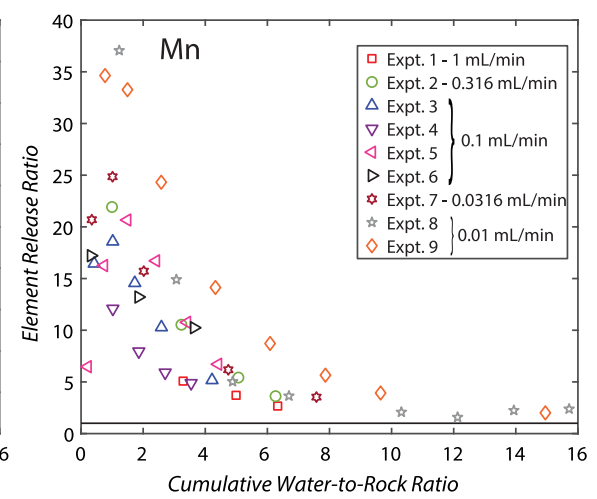

(b)

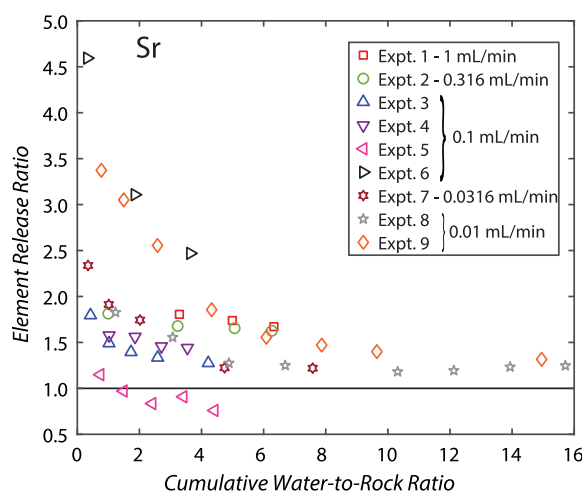

(c)

Figure 1 Ca normalised release ratios of (a) $\mathrm{Ba}$, (b) $\mathrm{Mn}$, and (c) Sr during flow-through experiments at flow rates ranging from 0.01 to $1 \mathrm{~mL} / \mathrm{min}$, plotted as a function of the cumulative water-to-rock ratio. At the conclusion of the slowest flow rate experiments $(0.01 \mathrm{~mL} / \mathrm{min})$, $\sim 60 \%$ of the $\mathrm{Ba}, \sim 30 \%$ of the $\mathrm{Mn}$, and $\sim 5 \%$ of the Sr had been removed from the cores, while only $\sim 3 \%$ of the Ca had been removed. 


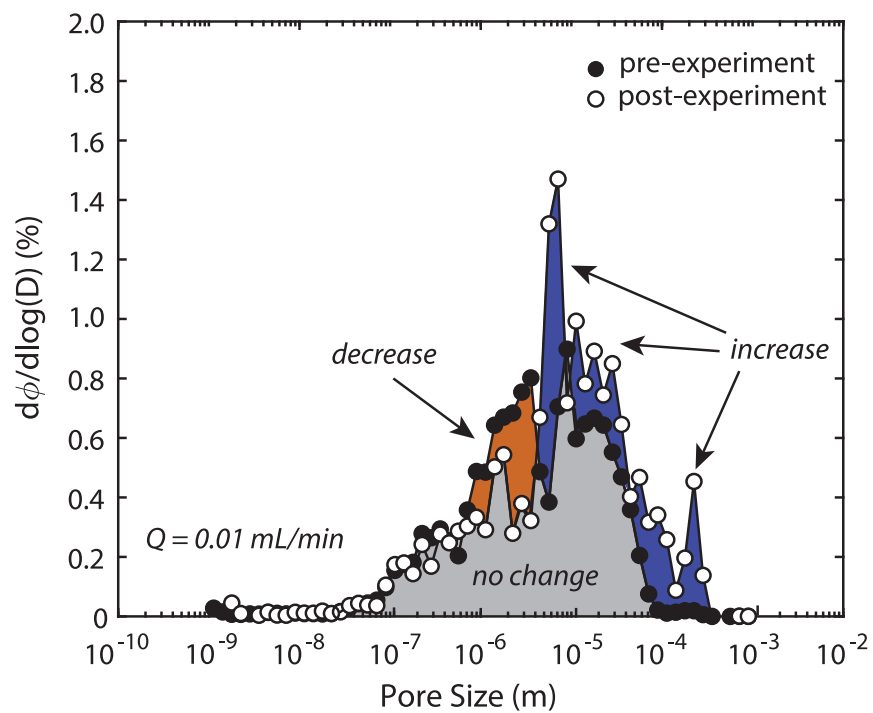

(a)

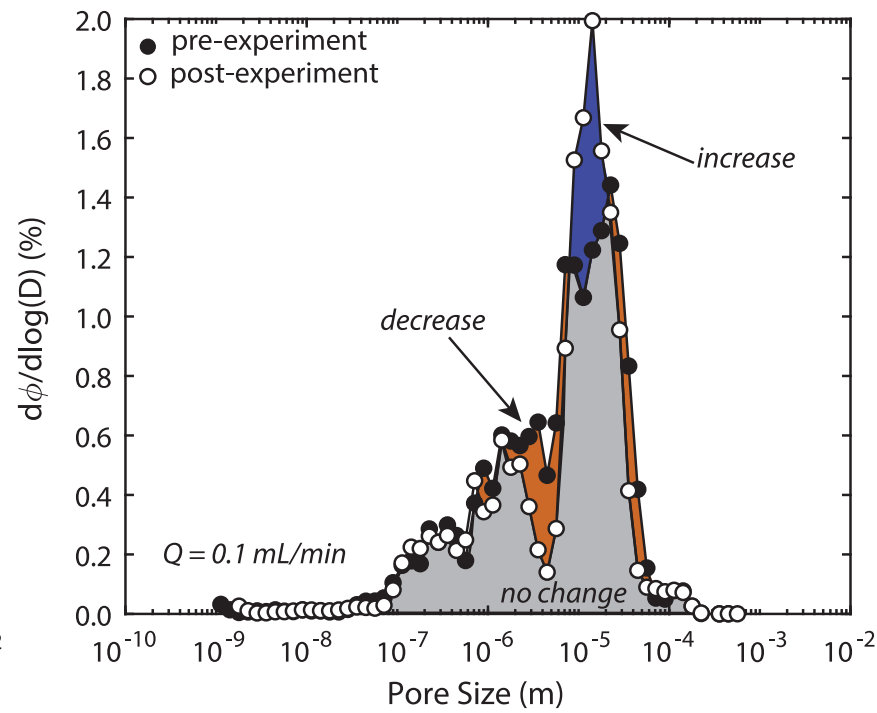

(b)

Figure 2 XRCT-USANS-SANS analysis of changes in pore size distribution, represented here as the $\%$ of the total sample volume ( $d \phi$ ) that can be attributed to a specific size range of pore sizes (dlog(D)) as calculated by the polydisperse spherical pore (PSDP) model. Integration under the curves yields the entire porosity of the sample. Analysis of pre-experiment (filled circles) and post-experiment (open circles) samples run at flow rates of (a) $0.01 \mathrm{~mL} / \mathrm{min}$ and (b) $0.1 \mathrm{~mL} / \mathrm{min}$ permits observation of the decreases and increases of the distribution of pores over specific size ranges.

characterisation of pores with diameters from $\sim 1 \mathrm{~nm}$ to $\sim 10 \mu \mathrm{m}$. These measurements were combined with a re-analysis of the XRCT imagery ( $8 \mu \mathrm{m}$ voxel size) to provide a quantitative description of the changes in porosity and pore size distribution over all relevant pore sizes. We chose two end member experiments representative of flow rates of 0.01 and $0.1 \mathrm{~mL} / \mathrm{min}$ (Expts. 3 and 8, respectively, from Luhmann et al., 2014) and two "pristine" samples from the same hand sample for the (U)SANS measurements.

With the addition of the pore size distribution calculations based on the combined XRCT-USANS-SANS data set, we can delineate which pores were participating in individual physical and chemical processes during the experiments (Fig. 2). Approximately half of the total pore volume in the dolomite cores occurs at pore sizes $<8 \mu \mathrm{m}$, and is thus invisible at the scale of our XRCT measurements (Table S-1). Pores $600 \mathrm{~nm}-5 \mu \mathrm{m}$ grew to $>5 \mu \mathrm{m}$, while pores $<600 \mathrm{~nm}$ showed no change, with slower flow rates yielding more, larger porosity. The combined chemical and physical analyses demonstrate that the largest $(\geq 5 \mu \mathrm{m})$ pores dominantly contribute to changes in porosity and permeability, consistent with these pores providing access to through-flowing fluids. However, these analyses and calculations of required interaction volumes (Supplementary Information) also strongly suggest that the smallest $(\$ 600 \mathrm{~nm})$ pores actively interact with the larger $(>600 \mathrm{~nm})$ pores, in turn suggesting that they greatly contribute to the non-stoichiometric release of trace elements, such that fluids are effectively interacting with almost the entire rock volume.

\section{Reactive Transport Modelling of Steady State Trace Element Fluxes}

The new observations were incorporated into a PFLOTRAN (Lichtner et al., 2019) micro-continuum reactive transport model in order to test our hypothesis regarding trace element mobility during carbonate interactions with $\mathrm{CO}_{2}$-rich fluids. A description of this model and its inputs is included in the Supplementary Information. In the case of dolomite dissolution, the results of the model demonstrate excellent agreement with output fluids sampled by Luhmann et al. (2014) (Fig. 3). Moreover, the results also demonstrate a reduction in the average (i.e. continuum-scale) rate of dolomite dissolution as the solution approaches equilibrium with respect to dolomite, but a near constant average dissolution rate of the trace components because the solution remains far from equilibrium with respect to these phases (Fig. 3d). In the case of the simulated trace components ( $\mathrm{Mn}, \mathrm{Sr}$, and $\mathrm{Ba}$ ), the outlet concentrations are $10 \%$ of the measured values i.e. $2.2 \mu$ molal versus $\sim 15-16 \mu \mathrm{mol} / \mathrm{kg}$ in the case of Mn (Fig. 3c); $0.18 \mu$ molal versus $1.5 \mu \mathrm{mol} / \mathrm{kg}$ in the case of $\mathrm{Ba}$, and $0.37 \mu \mathrm{molal}$ versus $1.1 \mu \mathrm{mol} / \mathrm{kg}$ in the case of $\mathrm{Sr}$. Because solid state diffusion rates of trace elements in carbonates at low temperatures only permit Angstrom-scale transport distances over our minute-to-hour fluid residence times (Stipp et al., 1992), this observation demands that the reaction rates of these trace components are $\sim 10 \times$ faster than that of dolomite.

The enhanced trace element reaction rates can be explained in two ways. Either: 1) the reaction rate of these trace components is significantly faster than that of the bulk dolomite because of the inherent energetic unfavourability of these elements in the dolomite structure (Marini, 2006); or 2) these trace elements are dissolving from nanoscale pores with a reactive surface area $\sim 10 \times$ greater than the dominant flow paths. In reality, each of these factors probably plays a role, but the latter is more strongly supported when considering not only the simulated, steady state reaction rates (to which the former likely also contributes) but also the extent of reaction in the dolomite surrounding these pores required to achieve such high trace element recoveries (Fig. 4). By virtue of their minute size, these pores have a much larger surface area-to-volume ratio and much smaller required interaction radii than their larger counterparts (Fig. 4), which would serve to facilitate both rapid dolomite equilibration and/or recrystallisation as well as rapid trace element extraction.

Together, our results can be used to inform a conceptual model for the role of a rock's various pore sizes in its hydrogeochemical evolution that assigns a specific role to both the 

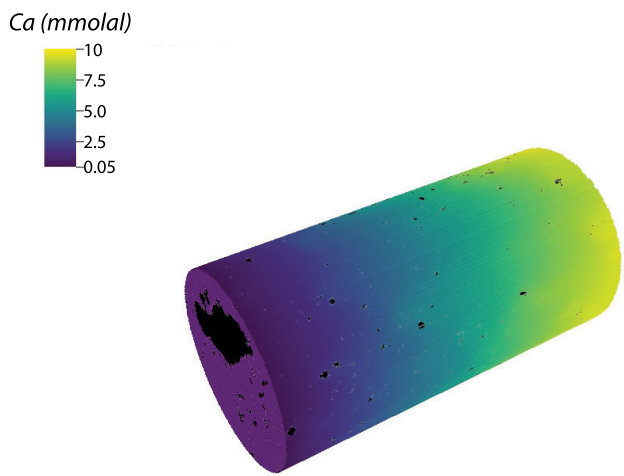

(a)

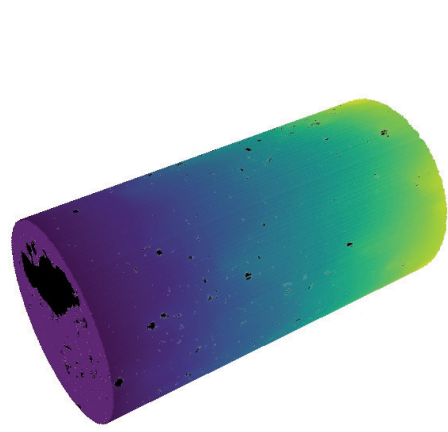

(c)

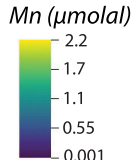

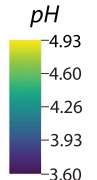

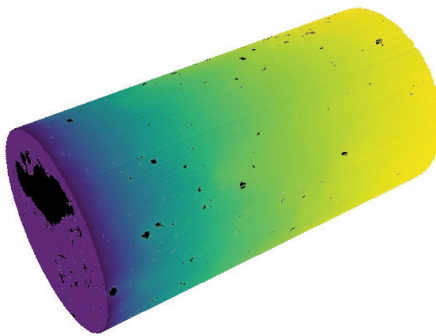

(b)

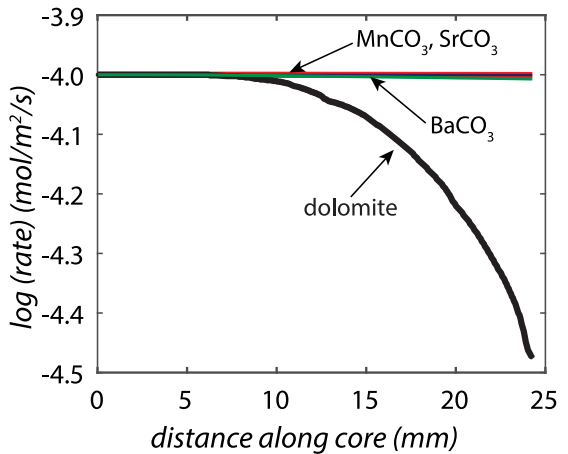

(d)

Figure 3 Results of micro-continuum reactive transport simulations on a post-experiment core from a $0.01 \mathrm{~mL} / \mathrm{min}$ injection experiment. (a) Ca concentration, (b) $\mathrm{pH},(\mathbf{c}) \mathrm{Mn}$ concentration, and (d) reaction rate in the centre-most element along the length of the core. In (a), (b), and $\mathbf{( c )}$, pore space is plotted in black.

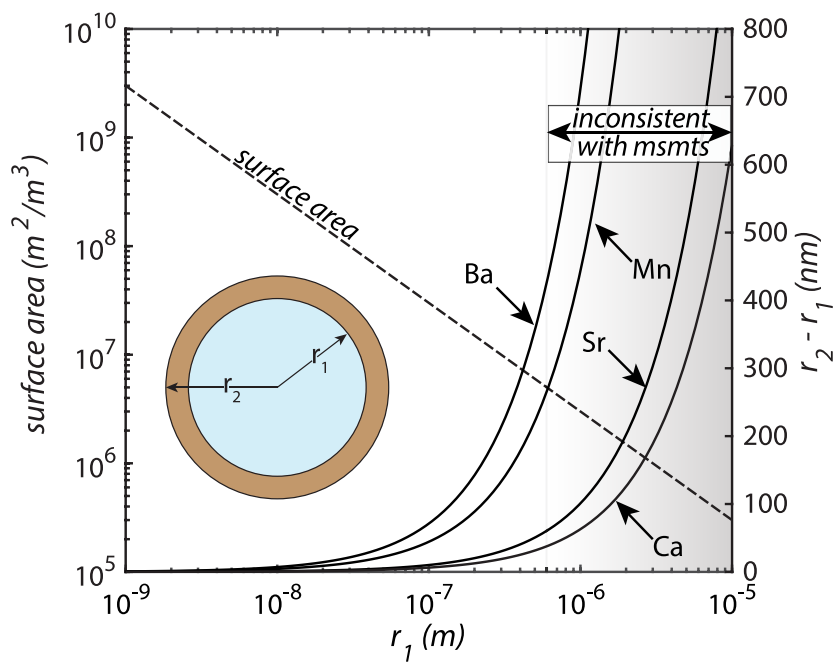

Figure 4 Visualisation of the radius of interaction $\left(r_{2}\right)$ required to produce experimentally measured element recoveries for pore radii $\left(r_{1}\right)$ ranging from $1 \mathrm{~nm}$ to $10 \mu \mathrm{m}$ and the corresponding specific surface area of these pores. Calculations assume that the rock's initial porosity is comprised of a uniform distribution of pores of radius $=r_{1}$. The difference between the trace element $(\mathrm{Ba}, \mathrm{Mn}, \mathrm{Sr})$ and $\mathrm{Ca}$ lines represents the radius from which these elements would have to have been removed without removing $\mathrm{Ca}$ to achieve observed recoveries. Figure 2 and accompanying analysis suggests these processes dominantly occurred in pores $<600 \mathrm{~nm}$ in size, where volumetric specific surface area is orders of magnitude higher and $r_{1}-r_{2}$ is $10 \mathrm{~s}-100 \mathrm{~s}$ of times lower than in pores $>600 \mathrm{~nm}$ in size. msmts, measurements. "visible" and "invisible" pores. In this conceptual model, fluids in the "visible" pores remain in a dissolution dominated, pore enlarging regime and probably do not contribute much more than the stoichiometrically expected mass of trace elements to the through-going fluids, since doing so would require extreme interaction volumes (Fig. 4). At the same time, fluids in "invisible" pores approach equilibrium with respect to primary dolomite, but remain far from equilibrium with respect to its trace components. The saturation states of the fluids in these pores thus allow the fluid to extract the trace elements without significantly increasing the pore size. This could be achieved through selective extraction of these elements from the dolomite structure due to structural misfit, or from dissolution of primary dolomite and re-precipitation of a purer phase. Although structural misfit is a plausible explanation for more rapid, instantaneous surface reaction rates, consideration of the interaction radii plotted in Fig. 4 (up to 10s to 100s of $15.95 \AA$; Steinfink and Sans, 1959) dolomite unit cells for "invisible" (<600 nm) pores) and the lack of change in the proportion of pores $<600 \mathrm{~nm}$ in size suggests that coupled dolomite dissolution-reprecipitation likely plays an important role. Regardless of the mechanism, the elevated recoveries demonstrate that the "invisible" pores are connected to the larger scale "visible" flow paths in the core, such that the fluids are efficiently leaching trace elements from a dense, nanoporous network, but only altering porosity in select core sections.

\section{Implications}

The results presented here have significant implications for both the development of hydrogeochemical models of sedimentary 
rocks as well as the use of carbonate rocks for the interpretation of past environmental conditions. We have shown that a very significant fraction of pores within carbonate rocks are present at scales that are not easily probed using conventional imaging techniques. Our combined analyses have shown that the largest pores in our samples contribute to the dissolution-driven porosity increases but that the smallest pores are most likely contributing to trace element release from the rock without significantly changing in size. This latter observation indicates that trace elements can be removed from dolomite rocks without leaving important telltale signs of alteration, such as pore enlargement or mineral etching. Increasingly, the trace element contents of ancient carbonate rocks are being used to interpret past Earth conditions (e.g., Gilleaudeau et al., 2016; Liu et al., 2016), yet our results show that the trace element content of these rocks can be very dramatically altered during water-rock interaction over geologic time. Although our experiments were run with $\mathrm{CO}_{2}$ concentrations higher than may be encountered in most carbonate reservoirs, they were also extremely short in duration when compared with diagenetic processes occurring over geologic time.

\section{Acknowledgements}

We thank the three anonymous reviewers for their insightful comments that helped to improve the clarity of the manuscript. Dr. Xin Gu (Pennsylvania State University) provided scripts for processing autocorrelation data and Hanford Deglint (University of Calgary) helped in creating Figure 2. Research support was provided by the National Science and Engineering Research Council of Canada (RGPIN-2018-03800), the Donors of the American Chemical Society Petroleum Research Fund, and the University of Calgary. MOS and X-ZK thank the Werner Siemens-Stiftung (Werner Siemens Foundation) for their support of the Geothermal Energy and Geofluids (GEG.ethz.ch) group at ETH Zurich, Switzerland. NCNR (U)SANS instrumentation was supported in part by the NSF under agreement DMR0944662, and ISIS beamtime was supported by the Science and Technology Facilities Council of the United Kingdom RB1610074. ISIS SANS data doi: 10.5286/ISIS.E.RB1610074.

Editor: Satish Myneni

\section{Additional Information}

Supplementary Information accompanies this letter at http:// www.geochemicalperspectivesletters.org/article2022.

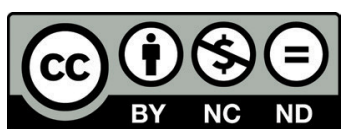

(C) 2020 The Authors. This work is distributed under the Creative Commons Attribution NonCommercial No-Derivatives 4.0 License, which permits unrestricted distribution provided the original author and source are credited. The material may not be adapted (remixed, transformed or built upon) or used for commercial purposes without written permission from the author. Additional information is available at http://www. geochemicalperspectivesletters.org/copyright-and-permissions.

Cite this letter as: Tutolo, B.M., Luhmann, A.J., Kong, X.-Z., Bagley, B., Alba-Venero, D., Mitchell, N., Saar, M.O., Seyfried, W.E. Jr. (2020) Contributions of visible and invisible pores to reactive transport in dolomite. Geochem. Persp. Let. $14,42-46$.

\section{References}

ANovitz, L.M., Cole, D.R. (2015) Characterization and analysis of porosity and pore structures. Reviews in Mineralogy and Geochemistry 80, 61-164.

ARCHIE, G.E. (1952) Classification of carbonate reservoir rocks and petrophysical considerations. AAPG Bulletin 36, 278-298.

CRAWSHAW, J.P., BOEK, E.S. (2013) Multi-scale imaging and simulation of structure, flow and reactive transport for $\mathrm{CO}_{2}$ storage and $\mathrm{EOR}$ in carbonate reservoirs. Reviews in Mineralogy \& Geochemistry 77, 431-458.

Gilleaudeau, G.J., Frei, R., Kaufman, A.J. KaH, L.C., Azmy, K., Bartley, J.K, Chernyavskiy, P., KNoll, A.H. (2016) Oxygenation of the midProterozoic atmosphere: Clues from chromium isotopes in carbonates. Geochemical Perspectives Letters 2, 178-187.

Li, L., Peters, C.A., Celia, M.A. (2006) Upscaling geochemical reaction rates using pore-scale network modeling. Advances in Water Resources 29, 1351-1370.

Lichtner, P.C., Hammond, G.E., Lu, C., Karra, S., Bisht, G., Andre, B., Mills, R.T., Kumar, J., FredericK, J.M. (2019) PFLOTRAN Web page. http://www. pflotran.org.

Liu, X.M., KaH, L.C., Knoll, A.H., Cu, H., Kaufman, A.J., Shahar, A., Hazen, R.M. (2016) Tracing Earth's $\mathrm{O}_{2}$ evolution using $\mathrm{Zn} / \mathrm{Fe}$ ratios in marine carbonates. Geochemical Perspectives Letters 2, 24-34.

Luhmann, A.J., Kong, X.Z., Tutolo, B.M., Garapati, N., Bagley, B.C., SaAr, M.O., SEYFried, W.E. JR. (2014) Experimental dissolution of dolomite by $\mathrm{CO}_{2}$ charged brine at $100^{\circ} \mathrm{C}$ and 150 bar: Evolution of porosity, permeability, and reactive surface area. Chemical Geology 380, 145-160.

Luquot, L., Gouze, P. (2009) Experimental determination of porosity and permeability changes induced by injection of $\mathrm{CO}_{2}$ into carbonate rocks. Chemical Geology 265, 148-159.

Ma, J., Querci, L., Hattendorf, B., SAar, M.O., KonG, X.Z. (2019) Toward a Spatiotemporal Understanding of Dolomite Dissolution in Sandstone by $\mathrm{CO}_{2}$-Enriched Brine Circulation. Environmental Science \& Technology 53, 12458-12466.

MARINI, L. (2006) Geological sequestration of carbon dioxide: Thermodynamics, kinetics, and reaction path modeling. Developments in Geochemistry, volume 11. Elsevier, Amsterdam, Oxford.

Molins, S., Trebotich, D., Steefel, C.I., Shen, C. (2012) An investigation of the effect of pore scale flow on average geochemical reaction rates using direct numerical simulation. Water Resources Research 48, 1-11.

Navarre-Sitchler, A.K., Maxwell, R.M., Silrila, E.R., Hammond, G.E., LichTNER, P.C. (2013) Elucidating geochemical response of shallow heterogeneous aquifers to $\mathrm{CO}_{2}$ leakage using high-performance computing: Implications for monitoring of $\mathrm{CO}_{2}$ sequestration. Advances in Water Resources 53, 45-55.

Plümper, O., Botan, A., Los, C., Liu, Y., Malthe-Sørenssen, A., Jamtveit, B. (2017) Fluid-driven metamorphism of the continental crust governed by nanoscale fluid flow. Nature Geoscience 10, 685-690.

Smith, M.M., Sholokhova, Y., Hao, Y., Carroll, S.A. (2013) $\mathrm{CO}_{2}$-induced dissolution of low permeability carbonates. Part I: Characterization and experiments. Advances in Water Resources 62, 370-387.

Steefel, C.I., Emmanuel, S., Anovitz, L.M. (Eds.) (2015) Pore-scale geochemical processes. Reviews in Mineralogy \& Geochemistry, Volume 80. The Mineralogical Society of America, Virginia, USA

STEINFINK, H., SANS, F.J. (1959) Refinement of hte crystal structure of dolomite. American Mineralogist 44, 679-682

StipP, S.L., Hochella, M.F., Parks, G.A., LeCKIE, J.O. (1992) $\mathrm{Cd}^{2+}$ uptake by calcite, solid-state diffusion, and the formation of solid-solution: Interface processes observed with near-surface sensitive techniques (XPS, LEED, and AES). Geochimica et Cosmochimica Acta 56, 1941-1954.

TuCKer, M.E., Wright, V.P. (2009) Carbonate sedimentology. John Wiley \& Sons.

Tutolo, B.M., Luhmann, A.J., Kong, X.Z., SAAR, M.O., Seyfried, W.E. (2014) Experimental observation of permeability changes in dolomite at $\mathrm{CO}_{2}$ sequestration conditions. Environmental Science and Technology 48, 24452452.

Wunsch, A., Navarre-Sitchler, A.K., Moore, J., Ricko, A., McCray, J.E. (2013) Metal release from dolomites at high partial-pressures of $\mathrm{CO}_{2}$. Applied Geochemistry 38, 33-47. 